\title{
Research on Rights Protection of Digital Inclusive Finance Consumer Meifang Xie
}

\author{
Department of economics and management, Minjiang University, Fujian of China
}

370833946@qq.com

\begin{abstract}
Keywords: Digital inclusive finance; Financial consumer; Digital technology; Consumers' rights and interests
\end{abstract}

\begin{abstract}
Development of inclusive finance driven by digital technology brings us benefit, risk and challenge. The increasingly obvious difficulty of protecting rights and interests of financial consumers is new challenge brought by digitalization. As digital inclusive finance is an emerging topic, research on rights protection of financial consumers is quite few. This paper sorts through the new challenge brought by development of digital inclusive finance to consumers and puts forward countermeasures and suggestion through giving definition of digital inclusive finance consumer in expectation to attract attention of all circles to protect consumers and help China seek for the optimal balance between innovation and risk during development of inclusive finance.
\end{abstract}

\section{Introduction}

The digital technology increase reachability of financial service. Big data, cloud computing, Blockchain and other financial science and technology effectively improves information collection, risk screening, and operation cost etc. However, we should notice that at the same time of bring convenience to financial clients, there also exists such problems as nonstandard financial product and service, frequent occurrence of financial consumption dispute, poor awareness of protecting financial consumers' rights and interests, to-be-improved risk identification ability etc. Senior Principle of G20 Digital Inclusive Finance approved by G20 Hangzhou Summit clearly puts forward the principle of "establishing responsible consumer protection which suits digital inclusive finance". It fully demonstrates the importance and urgency of client protection at the same time of developing digital inclusive finance in international society.

\section{Definition of Digital Inclusive Finance Consumer}

"Consumer" is proposed as a legal concept because, according to legal principle of fairness, ordinary consumers always find difficult to realize substantial fairness and freedom on condition of liberty of contract due to unseasonal, asymmetrical information acquisition, and disparity in economic strength [1]. Therefore, the law should give special protection to consumers. Financial consumer is sub-concept of consumer. Similarly, it should receive inclined protection and differential treatment. However, which group of consumers to be discussed in the paper should receive special protection? On December 2016, the first departmental regulation about protection of financial consumer--- Implementation Measure of People's Bank of China on Protection of Financial Consumers Rights and Interests was issued by People's Bank of China. It describes financial consumers as: consumers under the measure hereby refer to the natural person purchasing, using financial products and service provided by financial institution [2]. Obviously, such definition aims at all financial consumers. Advanced principle of digital inclusive finance was proposed in 2016 Hangzhou G20 meeting at which the digital inclusive finance was redefined. What's digital inclusive finance? It refers to providing a serious of regular financial service through utilizing digital technology to population who is unable to gain or absent of financial service. Therefore, "digital inclusive finance consumer" ought to be the natural persons who were previously unable to gain or used to be in shortage of financial service but can buy and use financial products and service now. There are two points to be noticed: the one, it is unnecessary that all financial consumers 
belong to objects under protection of digital inclusive finance consumer; the other, it isn't merely about products and service provided by traditional financial institution, Digital Inclusive Finance emphasizes the use of digital technology to provide financial service and products digitization innovation of traditional financing institution but also including internet financial products provided by some new non-financial institutions.

\section{Challenge and Risk confronted by Digital Inclusive Finance Consumer}

Challenge to Infrastructure. Three important digital infrastructures support availability of digital inclusive finance:

(1) Widespread and affordable networking, being supported by stable, reliable, fast and affordable network, there is possibility for realizing various digital financial transactions. Network outage may lead to interruption or failure of transaction which may cause consumers' bad experience even capital loss.

(2) Infrastructure for using digital financial service such as cell phone, panel computer and other mobile devices, cell phone is the most frequently used infrastructure for using digital financial service at present. Digital mobile financial service has relatively high requirement on function of cell phone. A smartphone is the first step. Then, faster and more stable $4 \mathrm{G}$ network should be connected, which is a big expenditure for clients, especially low-income clients or those in rural area. In addition, it increases the needs of study while using the smartphone.

(3) Improved credit information, it is more frequent for digital inclusive finance to provide financial service based on credit. Digitization-based method solves such problems as carrier of financial information and credit credentials etc. The effective collection and processing of financial consumers' information and accurate mastery of their possible line of credit make it quick and convenient to provide them with financial service so that finance may better benefit the general public [3]. Aiming at problems of digital inclusive finance consumer group such as no or limited credit record, the financial service providers must increase the operation cost to conduct field investigation for acquisition of effective information because of failure of gaining clients' credit information. Like "Backpack" Banks in many rural areas, credit information is still collected manually. In addition, it increases financial enterprise's operating risk. Meanwhile, for consumer, due to shortage of adequate credit information, their capital demand is difficult to be met or it involves higher cost for meeting their capital demand.

Challenge to Network Security. Digital Inclusive Finance should firstly depend on existence of digital and network technology, namely big data, cloud computing, Blockchain and other financial technologies. However, there are requirements on platform development technology, and risks of Hacker attack and system crashes and other problems which undermines clients' safe use.

Hacker intrusion caused by insufficient network security is likely to cause such circumstance as clients' capital getting stolen and some fraud incidents. According to a report of People's Daily in 2016, 78.2\% cyber citizens used to suffer leakage of personal identity information, online activity information of $63.4 \%$ internet citizens used to be disclosed, and $82.3 \%$ cyber citizens have personal experience of influence on daily life brought by personal information leakage.

Lack of Digital Technique and Knowledge. The digital inclusive finance consumers are mainly made up of the old, young, poor, low-income and poorly-educated people. Most of them are short of digital technique and knowledge; some even have no idea about smartphone not to mention how to use it. It is often the case of giving up using digital finance because have no idea of how to operate. The phenomena of capital loss even fraud incident caused by no knowledge of operation occur frequently. This is usually called "digital gap".

Shortage of Financial Knowledge. (1) Professional financial knowledge, it involves strong financial expertise in description of financial and service such as risk level, earning power of commodity and other relevant elements. Despite of complete and sufficient information provided by financing institutions, due to professional characteristics of financial commodity and service, it is difficult for financial consumer to have good understanding of all characteristic of such commodities and services. Coupled with rapid development of global financial innovation 
especially financial derivatives in recent years greatly increases complexity of financial products and non-transparency of market information so that the financial consumers find difficult to make accurate judgment of risk and conduct self-protection [5]. Moreover, financial service providers sometimes deliberately withhold information of commodity and service, or makes inadequate disclosure of product and service information for their own interests. Therefore, financial consumers are in disadvantaged position of serious information asymmetry in trading activity. They often find difficult to distinguish authenticity of products or get the key information in product descriptions.

(2) Inadequate financial experience, we learn from frequent occurrence of "schoolyard loans" that a considerable number of college students are in urgent need of financial experience and knowledge. They often sign some unequal loan agreement under circumstance of no clear understanding about loan flow, credit conditions and payback mode so that an original loan of several thousand Yuan evolves to ten thousands or hundreds of thousands Yuan due to high interest rate.

\section{Suggestions on Strengthening Protection of Digital Inclusive Finance Clients}

Strengthening Construction of Infrastructure, Laws and Regulation; Speeding up Change of Supervision Ways. 1. Infrastructure Construction. (1) Network Construction, digital inclusive finance depends on the ubiquitous internet network. However, in face of the low-income or disadvantaged digital inclusive finance consumer, we should consider their affordable amount of data cost. In 2015, the State Council issued the Guidance on Accelerating Construction of High-speed Broadband Network and Promoting Network Speed-up and Cost Reduction which proposed to spend three years on accelerating construction of fully fiber-optic cyber city and the fourth generation mobile communication network, greatly improving network speed rate and effectively reducing network charges[6]. The government should cooperate with mobile communication provider to increase network facilities in remote and mountain areas, large-scale construction to lower the cost.

(2) Establishment of credit system, clients of digital inclusive finance may haven't enjoyed financial service or received inadequate financial service previously, which leads to incomplete credit information. However, if they fail to be provided with continuous financial service, the credit information remains to be incomplete and it falls into vicious cycle. In this respect, we may learn from experience of the first experimental plot of inclusive finance reform-Lankao County. The credit history may be created through credit loan. Firstly, we may depend on the government to provide each family with small loans so as to get credit information. Meanwhile, the credit system should conform to the digitization process, providing big data mode and breaking "data barrier. A complete credit information system should be established. Simultaneously, an information sharing system which can be internally shared within financial institutions should be established.

2. Formulating specialized laws and regulations in line with development of Digital Inclusive Finance. The law is powerful backup force for protection of consumers' rights and interests. United States, European Union and some other developed countries where internet finance achieves earlier development, have clearly definition about supervision of digital finance. Some countries carry out specific legislation; while others add corresponding clauses on basis of previous law. Therefore, aiming at protecting rights and interests of consumers, China should formulate super-level Law for Protecting Rights and Interests of Financial Consumer based on our practical condition so that there are laws to abide by when dispute happens or clients seek assistance. Meanwhile, it provides certain legal basis for strengthening supervision of protecting clients' rights, financial education, dispute complaint mechanism and right of clients' privacy etc.

3. Innovating the regulatory and supervision mode. According to Peking University Institute of Internet Finance, many problems related to digital finance are associated with absence of supervision or inappropriate supervision. In order to ensure sound development of digital inclusive finance, a set of effective regulatory and supervision framework must be established as soon as possible so as to achieve balance between innovation and risk [7]. 
At present, government's supervision for financial field is inclined to prudential supervision, emphasizing institution and ignoring consumers. Supervision for financial deeds and financial function is still in muddled state [8]. However, from perspective of digital inclusive finance development, Convergent and platform development become more and more popular. The characteristic of "mixed" operation becomes increasingly obvious. Therefore, we should learn from regulatory and supervision mode of Britain and Canada to establish the "double-peak" supervision mode so as to separate the behavioral supervision from prudential supervision, better balance relationship between prudential supervision and behavioral supervision and conduct effective supervision and interference on financial institution and financial products, make good protection of financial consumers' rights and interests.

Strengthening Self-Construction of Digital Inclusive Finance Provider and Industry Self-Regulation. 1. Improving reliability and stability of platform. Platform is the carrier for developing digital inclusive finance business, including webpage construction of PC terminal and mobile APP construction of ME terminal. Network outage, unreliable platform, complicated platform interface are problems frequently complained by digital financial clients. The main task for our governmental sector is construction of network infrastructure, to improve network coverage. And the digital finance providers should focus on strengthening construction of their own trading platform.

(1) Carrying out regular inspection and real-time test on network system; formulating complete and continuous business plan and contingency plan.

(2) Making it convenient to use client interface, it is beneficial for clients and service provider to improve client interface. Improvements may be made from several following aspects: firstly, besides the text description, the interactive language is added to reply system sending message and operation guide, which provides convenience to users of low level of literacy. Secondly, we consider using alternative password and making use of recognition system or dynamic password generator of biological information. Meanwhile, improvement of such biological recognition system, to a large extent, mitigates the risk caused by digital inclusive finance's extreme dependence on mobile device terminal. Thirdly, we should design interface or program which is good for reducing keyboard input mistake, for instance, simple steps are added to help clients to confirm correct beneficiary information (adoption of "Verification Code" or displaying name of payee through address list before remittance). Fourthly, a period of cooling-off period may be designed so that the clients may decide to cancel duration of financial products after signing the contract. The cooling-off period is conducive to compensating the clients under circumstance of changing their minds or possibility of suffering capital pressure as well as preventing possible fraud incident. According to provision of Central Bank of China on December $1^{\text {st }} 2016$, since December $1^{\text {st }} 2016$, ATM -based transfer of personal clients with debit card (excluding bank-in transfer to remitter) will be disposed 24 hours later after being accepted by bank. Within the 24 hours after acceptance, the clients may apply for cancelling the transfer through telephone or counter [9], which gives expression to the cooling-off period.

2. Strengthening protection of clients' data and information, in the era of digitization, possession of data means acquisition of wealth. Information of a number of clients may be left through digitization financial transaction; while network insecurity and management imperfection within financial enterprises may cause disclosure of client information. Therefore, financial enterprise should strengthen hierarchical management and control over data so as to present fraudsters and other unauthorized people from obtaining data and cause damage to consumers.

3. Establishing clear complaint settlement mechanism

For digital finance provider, it is difficult to synchronize equipment upgrading with rapid development of business. Coupled with weakness of clients, a large quantity of complaints and great needs of assistance will be required. Therefore, it is necessary for financial service supplier, especially those in absence of entity, to establish a clear platform complaint mechanism.

(1) The specialized interface should clearly guide the clients' complaint when encountering problems. An unblocked and inexpensive complaint passageway should be established. 
(2) Improving the service standard of complaint and assistance, for instance, making a promise about complaint resolution time, establishing the complaint follow-up system, providing clients with complaint serial number for their query of progress, reporting settlement progress at regular time through email or telephone or platform interaction.

(3) When individual service provider is unable to solve clients' complaint and assistance, it may be submitted to industry association. Industry self-discipline mechanism, and diversified financial consumption dispute settlement mechanism should be formed to increase clients' trust on digital inclusive finance industry.

Consumers are Required to Raise Their Awareness of Self-Protection and Self-Study. Increasingly fierce fraudulent conducts of lawbreakers, cleverer and cleverer means are closely associated with financial clients' compromise and the absence of financial knowledge. According to the survey, more than $60 \%$ financial consumers have inadequate understanding about rights protection. Consumers having limited understanding account for $50.1 \%$ of total financial consumers, those in extreme shortage of relevant knowledge take up $11.3 \%$ and those having relatively comprehensive understanding merely take up 9.3\% [10.1]. From perspective of knowledge channel, the mass media is taken as the main channel by most consumers. A merely small number of consumers take initiative to learn relevant knowledge. In the 504 copies questionnaire surveys delivered by the author in Fujian Province, the question of "what the channels you usually use to get financial knowledge?" The results are as follows:

Table 1 The channel to financial knowledge

\begin{tabular}{|c|c|}
\hline Channel & Proportion[\%] \\
\hline Buying financial books independently & $25.40 \%$ \\
\hline $\begin{array}{c}\text { Financial Knowledge Brochure of Banks and } \\
\text { other financial institutions }\end{array}$ & $42.66 \%$ \\
\hline $\begin{array}{c}\text { Social Promotion Acitivity about Financial } \\
\text { Knowledge }\end{array}$ & $27.78 \%$ \\
\hline Through internet platform & $59.13 \%$ \\
\hline Others & $17.86 \%$ \\
\hline
\end{tabular}

During the process of promoting digital inclusive finance, we should pay attention to raising consumers' awareness of right protection, innovate and renovate the internet finance by starting from demands of consumers [10.2]. Depending on the legal weapon, actively seeking for resolution mechanism, and bravely expressing your needs are important links for putting an end to illegal practices. Only in this way, will they safeguard their rights and interests. Meanwhile, clients should take initiative to learn financial knowledge, try to avoid speculation, enhance the awareness of investment and reduce blind investment, increase risky investment. A plenty of clients suffer benefit lost as a result of greedy and fluke mind. For instance, coveting small gains; investing products of high earning rate but in obvious violation of financial commonsense. Therefore, in order to improve the environment of financial consumer protection, regulation and supervision of government is indispensable. Consumers' awareness of rights protection is of vital importance.

\section{Reference}

[1] Cui Zhenzhen, Deng Lulu. "Rights and Interests Protection of Financial Consumer---concentrating on concept definition" [J], Academic Journal of Tianjin University (Social Science Edition), 2016 (1)

[2] Sohu Finance \& Economics. "Implementation Measure of People's Bank of China on Protection of Financial Consumers Rights and Interests issued by Central Bank of China” [EB/OL], http://mt.sohu.com/business/d20161229/122960246_465385.shtml

[3] Zhejiang E-commerce.com . "Wang Yongli---Letv Finance CEO: Credit System is of 
great importance for development of digital inclusive finance" [EB/OL], http://ec.zjol.com.cn/system/2016/09/25/021310537.shtml

[4] Newhua.com. Jingdong12GB user data is suspected to be disclosed, including ID number, password etc. [EB/OL], http://www.newhua.com

[5] Gao Tiantian, Chenchen. "Financial Consumer Protection: Theoretical Analysis, Reflect on Governmental Function and Policy" [J], Economy and Social System Comparison ,2015 (1)

[6] Guan Tianyu. " 4G Network is expected to realize urban-rural coverage in 2017”, Computer and Network, 2015 (10)

[7] Li Guanglei. Chinese Digital Inclusive Finance "Pathfinding" [N], Financial Times, 2016-11 $-14$

[8] Jiao Jinpu. "Current Situation of Chinese Financial Consumer's Rights Protection and Reflection" [J], Tsinghua Financial Review ,2014 (10)

[9] Eastday.com. CMBC Detailed Interpretation of New Regulation on Bank Account Management[EB/OL], http://finance.eastday.com/m/20161129/u1ai10091147.html

[10] Jiang Xinxin. Strengthening Rights and Interests Protection of Digital Inclusive Finance Consumption [N], Financial Times, 2016-10-17. 